\title{
NUMERICAL MODELLING OF BANK EROSION IN A CIRCULAR CHANNEL WITH COHESIVE BANKS INCLUDING EFFECT OF SLUMP BLOCKS
}

\author{
Kattia Rubi ARNEZ FERREL ${ }^{1}$, Ichiro KIMURA ${ }^{2}$ and Yasuyuki SHIMIZU3 \\ ${ }^{1}$ Master Student. Graduate school of engineering, Hokkaido University \\ (North 13, West 8, Kita-ku, Sapporo 060-8628, Japan) \\ E-mail: rubikraf@eis.hokudai.ac.jp \\ 2 Dr. of Eng. Assoc.Prof. Graduate school of engineering, Hokkaido University \\ (North 13, West 8, Kita-ku, Sapporo 060-8628, Japan) \\ E-mail: i-kimu2@eng.hokudai.ac.jp \\ ${ }^{3}$ Dr. of Eng. Prof. Graduate School of engineering, Hokkaido University \\ (North 13, West 8, Kita-ku, Sapporo 060-8628, Japan) \\ E-mail: yasu@eng.hokudai.ac.jp
}

\begin{abstract}
In this paper two numerical models are analyzed and then, the advantages of each model are combined in order to simulate bank erosion in a river bend. The coupled model includes the effect of slump blocks produced by cantilever failure in cohesive banks and a corrected velocity profile that takes into account the lateral inclination of velocity profile at a bend. The model is developed for simulating flow in an infinitely long circular channel and is applied to seven cases. Four cases are tested for cohesive banks and three cases in non-cohesive materials. The capacity of the model to simulate the effects of slump blocks in cohesive banks is qualitatively analyzed and, for the case of non-cohesive banks, the numerical model is validated using experimental data obtained from the literature.
\end{abstract}

Key Words: cantilever failure, $1 D-2 D$ cross sectional model, bank erosion, numerical simulation, cohesive banks, slump blocks, secondary current of the first kind

\section{INTRODUCTION}

River systems are in constant movement and in meandering rivers, the lateral change of the riverbanks in time is described by the meander migration.

Bank erosion is responsible, together with bank accretion, for the migration and growth of river meanders ${ }^{1)}$. The importance of the topic relies in the fact that it can affect the infrastructure that has been established close to the riverbanks, and even sometimes can become a threat for human lives. Furthermore, the complex interactions among the variables that compose this phenomenon makes the study of this topic really challenging.

Many researchers have developed numerical models trying to simulate the bank failure mechanisms in riverbanks. However, very few take into account the effect of slump blocks.

In 1995, Garcia et al, presented a mathematical model for meandering streams coupled with a stream bank erosion model to predict lateral migration. Nevertheless, their model was limited by the bank erosion model which considered that the erosion rate was proportional to the near-bank velocity ${ }^{2)}$.

Later, Motta et al in 2014, presented their investigation about the effect of bank failures in the meander migration by parameterizing the impact of mass failure on bank retreat and river migration rates through a reduction factor applied to the fluvial erosion rate ${ }^{3)}$. However, they did not consider the effect of the slumps blocks on the bank geometry, because at that time there was not enough information about this topic.

Recently, a complete investigation about cantilever failure in cohesive banks was presented by Patsinghasanee et $\mathrm{al}^{4), 5)}$. By experimental and numerical means, they showed a physical description of the mechanisms of cantilever failure considering two types of bank failure: cantilever and planar failures. However, the model is limited to a straight channel because the effect of curvature on the transverse 
velocity profile was not considered.

Herein, the main objective of this paper is to study the effect of slump blocks produced by cantilever failure in a curved channel by numerical modelling. For simplicity of calculation, we focus on well-developed flows in an equilibrium state in an infinitely long circular channel with a constant curvature radius.

In order to achieve the aforementioned objective, we coupled two numerical models: Patsinghasanee et al's model (cantilever failure model) and Garcia et al's model (the part of the flow model). First, Patsinghasanee et al's model was improved by taking into account the effect of secondary current of the first kind in the lateral sediment transport equation. Then, the velocity profile was improved using the mathematical solution for the near-bank velocity given by Garcia's et al.

By incorporating these modifications and coupling the models; we were able to represent the bank erosion process including the effect of slump blocks in a circular channel.

\section{METHODOLOGY}

In this section, we present an overview of the two numerical models to be merged and we describe the process followed in order to perform the coupling of the models.

\section{(1) Flow model in Garcia et al (1996)}

Garcia et al's model is divided in two main parts: the hydrodynamics and the bank erosion. We only use the hydrodynamics module.

The hydrodynamic part is based on the two-dimensional St. Venant depth-averaged equations and the depth-averaged continuity equation as follows:

$$
\begin{aligned}
& \frac{1}{1+n^{*} C^{*}} u^{*} \frac{\partial u^{*}}{\partial s^{*}}+v^{*} \frac{\partial u^{*}}{\partial n^{*}}+\frac{C^{*}}{1+n^{*} C^{*}} u^{*} v^{*}= \\
& -\frac{1}{1+n^{*} C^{*}} g^{*} \frac{\partial H^{*}}{\partial s^{*}}-\frac{\tau_{s}^{*}}{\rho^{*} D^{*}} \\
& \frac{1}{1+n^{*} C^{*}} u^{*} \frac{\partial v^{*}}{\partial s^{*}}+v^{*} \frac{\partial v^{*}}{\partial n^{*}}+\frac{C^{*}}{1+n^{*} C^{*}} u^{* 2}= \\
& -g^{*} \frac{\partial H^{*}}{\partial n^{*}}-\frac{\tau_{n}^{*}}{\rho^{*} D^{*}} \\
& \frac{1}{1+n^{*} C^{*}} \frac{\partial\left(u^{*} D^{*}\right)}{\partial s^{*}}+\frac{\partial\left(v^{*} D^{*}\right)}{\partial n^{*}}+ \\
& \frac{C^{*}}{1+n^{*} C^{*}} v^{*} D^{*}=0
\end{aligned}
$$

where $s^{*}$ and $n^{*}$ are the streamwise and transverse coordinates, $u^{*}$ and $v^{*}$ are the velocity components in the streamwise and transverse directions, $H^{*}$ is the water surface elevation, $\tau_{s}{ }^{*}$ and $\tau_{n}{ }^{*}$ are the local bed shear stresses in the streamwise and transverse directions, $\rho^{*}$ is the water density, $g^{*}$ is gravity acceleration $\left(=9.81 \mathrm{~m} / \mathrm{s}^{2}\right)$ and $D^{*}$ is the local flow depth. The local curvature of the channel centerline $C^{*}$ is defined as:

$$
C^{*}\left(s^{*}\right)=-\frac{\partial \theta}{\partial s^{*}}=\frac{1}{r^{*}}
$$

where $\theta$ is the angle between the channel centerline axis and the horizontal axis and $r^{*}$ is the local radius of curvature.

Assuming a constant width and a linear transverse bed elevation in function of the curvature, a mathematical solution was found for the near-bank perturbation velocity $u_{b}$ :

$$
\begin{gathered}
u_{b}(s)=a_{1} e^{-a_{2} s}+a_{3} C(s)+a_{4} e^{-a_{2} s} \int_{0}^{s} C(s) e^{a_{2} s} d s \\
a_{1}=u(0)+\chi C(0) \\
a_{2}=2 C_{f 0} \beta \chi \\
a_{3}=-\chi \\
a_{4}=C_{f 0} \beta\left[\chi^{5} F_{0}^{2}+(\alpha+1) \chi^{2}\right. \\
\left.+5 \sqrt{C_{f 0}} \chi^{2}\left(\alpha+\chi^{3} F_{0}^{2}\right)\right] \\
\chi=\left(\frac{S_{0}}{S_{v}}\right)^{\frac{1}{3}}
\end{gathered}
$$

where $\beta=B^{*} / D_{o}, B^{*}$ is the channel half-width, $\alpha$ is a constant coefficient that controls the steepness of the transverse slope of the channel bed, $S_{o}$ is the averaged meandering channel slope, $D_{o}$ is the reach-averaged water depth, $S_{v}$ represents the valley slope and $F_{0}$ denotes the Froude number. The friction coefficient $C_{f 0}$ can be calculated as:

$$
C_{f 0}=6+2.5 \ln \left(\frac{D^{*}}{2.5 d_{s}{ }^{*}}\right)
$$

where $d_{s}{ }^{*}$ is a measure of the bed grain size.

The bank erosion was calculated using the bank migration approach of Ikeda et al (1981), where the rate of erosion is proportional to the near-bank flow velocity. In Garcia et al's model all the variables with an asterisk indicate a dimensional value (from Equations (1) to (6)). A more detailed description of the model can be found in the original paper ${ }^{2}$.

\section{(2) Patsinghasanee et al's model (2016)}

The cantilever failure and the different stages that describe the phenomenon are taken into account in this model. The authors observed in their experiments that the cantilever failure phenomenon follows four stages: 1) fluvial erosion, 2) development of tension cracks, 3) failure of overhanging part and fall of slumps blocks in the bed channel and, 4) slump 
blocks decomposition and sediment transport of the banks ${ }^{4}$.

Based on these observations the authors conceptualized the problem and developed a cross sectional model to represent the bank erosion phenomenon in rivers with cohesive banks.

The model uses a triple grid approach, considering a coarse one-dimensional (1-D) grid for the flow calculations and a 2D-fine grid for computation of the soil.

The fluvial erosion in the model was calculated using an excess shear stress formula given below:

$$
\varepsilon=k_{d}\left(\tau_{b 0}-\tau_{b c}\right)^{a}
$$

where $\varepsilon$ is the fluvial erosion rate of the bank $(\mathrm{m} / \mathrm{s})$, $k_{d}$ is the erodibility coefficient $\left(\mathrm{m}^{3} /(\mathrm{N} \mathrm{s})\right), \tau_{b 0}$ is the actual shear stress applied by the flow $(\mathrm{Pa}), \tau_{b c}$ is the critical shear stress of the bank (Pa) and $a$ is an exponent generally assumed to be equal to one.

The actual shear stress was calculated using the following formula:

$$
\tau_{b 0}=\rho g R_{j} i
$$

where $R_{j}$ is the hydraulic radius in each calculation cell $\left(A_{j} / P_{j}\right), A_{j}$ is the cross-sectional area of a cell, $P_{j}$ is the wetted perimeter of a cell, $j$ is the lateral cell number and $i$ is the energy slope. In the model uniform flow conditions were assumed and therefore, the energy slope was set equal to the bed slope.

The critical shear stress $\tau_{b c}$ was evaluated by the empirical formula of Julian and Torrez ${ }^{6}$ based on the percentage of silt-clay content $S C$.

$$
\begin{aligned}
& \tau_{b c}=0.1+0.1779(S C)+0.0028(S C)^{2} \\
& -2.34 \times 10^{-5}(S C)^{3}
\end{aligned}
$$

The velocity in each cell $u_{j}$ was calculated using Manning's formula:

$$
u_{j}=\frac{1}{n_{m}} R_{j}^{2 / 3} i^{\frac{1}{2}}
$$

where $n_{m}$ is the Manning roughness parameter along the channel calculated using the Manning-Strickler equation $\left(k_{s}{ }^{1 / 6} / 7.66 g^{1 / 2}\right)$ and $k_{s}$ is the roughness height defined as $1.5 d_{50}$.
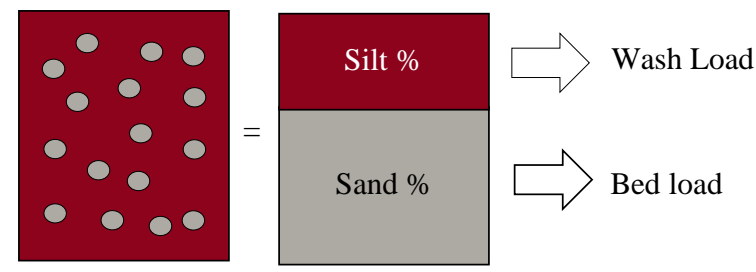

Slump block

Fig.1 Schematic representation of the slump block's decomposition. The slump block is considered to be a mixture of silt and sand (grey: sand; red: silt).

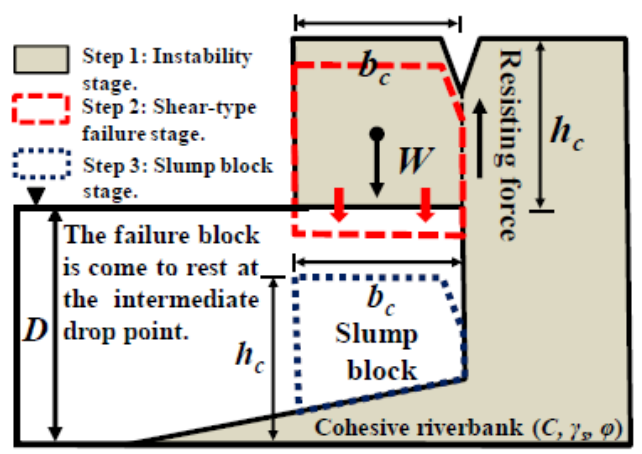

(a) Shear-type failure.

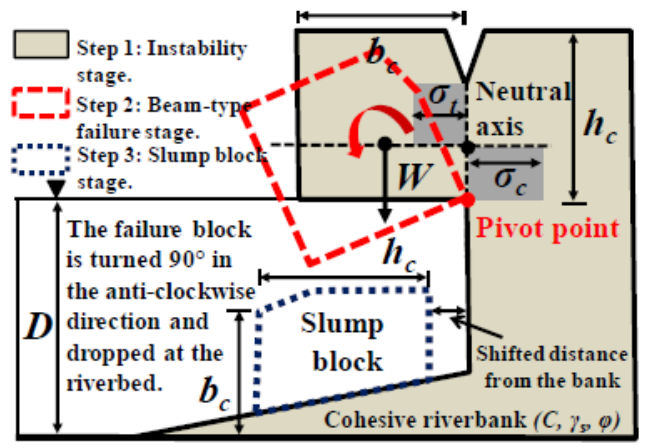

(b) Beam-type failure

Fig.2 Cantilever failure mechanisms ${ }^{4)}$.

For the next stage, the cantilever failure was analyzed using a limit equilibrium analysis. Two types of failure were considered: shear and beam failure.

Shear failure occurs when the shear stress along the vertical plane of the overhanging block weight exceeds the resistance force of the cohesive bank ${ }^{4)}$ as shown in Fig. 2a. As a consequence, the slump block falls directly into the water maintaining its initial dimensions.

On the other hand, the beam failure takes place when the rotational moment of the overhanging block overcomes the resistive moments of the soil strengths in the tension and compression zone $e^{4)}$ as illustrated in Fig. 2b. The overhanging block falls into the water rotating 90 degrees from the pivot point which is located in the lowest edge of the failure plane.

The criteria used to determine whether shear or beam failure will occur depend on the safety factor with the smaller value. The program calculates the factor of safety for shear and beam failure in each vertical section. Then, both values are compared and the lesser value is selected. If the value is less than one then the program assumes that the failure occurred.

Once the failure occurs the material is deposited in the riverbed in front of the banks and the decomposition process begins. The dropped material (slump blocks) are decomposed in two different materials: sand and silt. The silt is assumed to become wash 
load, and the failed sand acts as bedload ${ }^{4)}$ as shown in Fig. 1.

An important assumption of this model is considering that the strength of the slump block is reduced once it falls into the riverbed, because the slump block experienced a disturbance due to the dropping ${ }^{4}$.

In the model the sediment transport can be calculated selecting between the equations proposed by Ashida and Michiue (1972) (Equation (11)) and Meyer Peter Muller (1948) (Equation (12)):

$$
\begin{gathered}
q_{b s}=17 \tau_{*}^{\frac{3}{2}}\left(1-\frac{\tau_{c}^{*}}{\tau^{*}}\right)\left(1-\sqrt{\frac{\tau_{c}^{*}}{\tau^{*}}}\right) \sqrt{s_{g} g D_{50}{ }^{3}} \\
q_{b s}=8\left(\tau^{*}-\tau_{c}^{*}\right)^{1.5}
\end{gathered}
$$

where $\tau^{*}$ is the non-dimensional bed shear stress, $s_{g}$ is the specific weight of sediment $(=2.65)$ and $\tau_{c}{ }^{*}$ is the non-dimensional critical bed shear stress (Iwagaki's equation, 1956).

The sediment transport rate in the lateral direction $q_{b n}$ was evaluated using the Hasegawa's equation, neglecting the secondary current of first kind because a straight channel was considered, as given:

$$
q_{b n}=-q_{b s} \sqrt{\frac{\tau_{c}^{*}}{\mu_{s} \mu_{k} \tau_{*}}} \frac{\partial z_{b}}{\partial y}
$$

where $z_{b}$ is the bed elevation; $\mu_{s}$ and $\mu_{k}$ are the static $(=1.0)$ and dynamic $(=0.45)$ friction factors and $y$ is the coordinate component in the lateral direction.

The bed deformation was calculated using a continuity equation of the bed as:

$$
\frac{\partial z_{b}}{\partial t}+\frac{1}{1-\lambda}\left(\frac{\partial q_{b n}}{\partial y}\right)=0
$$

where $t$ is time and $\lambda$ is the porosity of the material $(=0.4)$.

The numerical result was validated using experimental data showing that it was able to reproduce the effect of slump blocks, reducing fluvial erosion and reinforcing the banks in a straight channel ${ }^{4), 5}$.

\section{(3) Coupled model}

Both models present advantages and disadvantages. Garcia et al's model includes the effect of curvature in the velocity profile. On the other hand, Patsinghasanee et al's model include the effect of

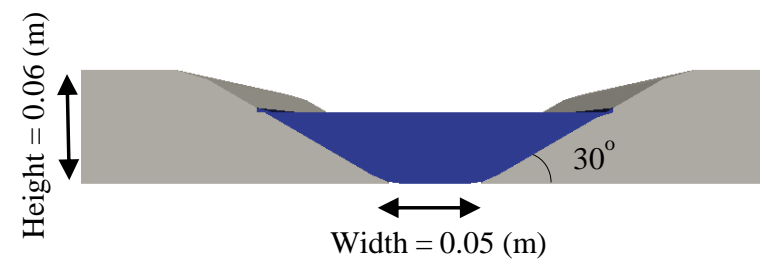

Fig.3 Cross sectional view of the initial conditions for non-cohesive banks (grey: sand; blue: water).

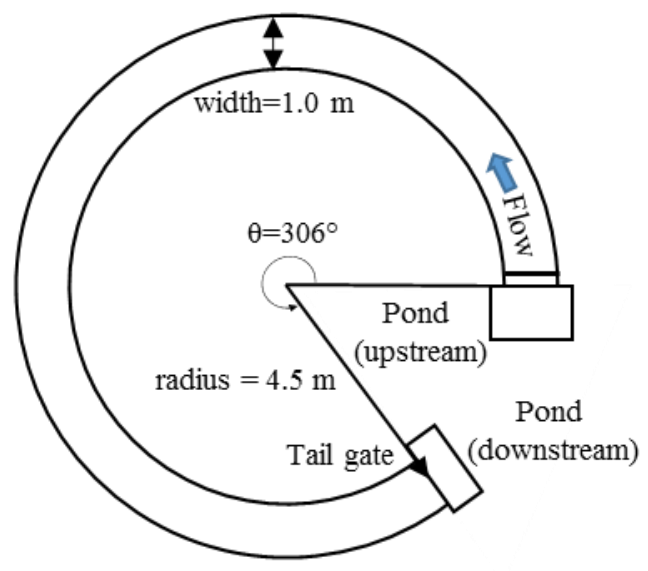

Fig.4 Schematic top view of the annular flume in the experiments of Fukuoka et al for non-cohesive banks ${ }^{7}$.

slumps blocks in cantilever failure. In order to simulate flow in a river bend it is important to include both effects.

Due to the complex nature of the problem the following assumptions were made.

We considered an infinitely long channel with constant radius of curvature. In this idealized axisymmetric situation, the flow it is said to be fully-developed when it does not change along the streamwise direction and with time ${ }^{1)}$.

Under these conditions the dimensionless near-bank velocity $u_{b}$ was derived from Equation (5), given as:

$$
u_{b}=C\left(a_{3}+\frac{a_{4}}{a_{2}}\right)
$$

where $a_{2}, a_{3}$, and $a_{4}$ are calculated using equations (5c), (5d) and (5e) respectively. The dimensionless curvature is calculated as follows: $C=B^{*} / r^{*}$.

In order to consider the effect of the curvature in the velocity profile, a weight function calculated with the near-bank velocity was used to correct the velocities in the model of Patsinghasanee et al.

$$
u_{c j}=u_{j}\left(1+u_{b} n_{j}\right)
$$

Where $u_{c j}$ are the corrected velocities and $u_{j}$ are the velocities obtained from Equation (10) and $n_{j}$ is the non-dimensional coordinate in lateral direction defined as $n_{j}=n_{j}{ }^{*} / B^{*}$.

Furthermore, the effect of the secondary flow was considered in the equation of the sediment transport rate in the lateral direction that was calculated using Hasegawa's equation:

$$
\begin{gathered}
q_{b n}=\frac{u_{b n}}{u_{b s}}-q_{b s} \sqrt{\frac{\tau_{c}^{*}}{\mu_{s} \mu_{k} \tau_{*}}} \frac{\partial z_{b}}{\partial y} \\
u_{b n}=-N_{*} \frac{D^{*}}{r^{*}} u_{b s}
\end{gathered}
$$


Table 1 Simulated cases

\begin{tabular}{|c|l|}
\hline \multicolumn{2}{|l|}{ Non-cohesive banks } \\
\hline Case & Characteristic \\
\hline 1 & Coupled model \\
\hline 2 & $\begin{array}{l}\text { Without correction in the velocity } \\
\text { profile }\end{array}$ \\
\hline 3 & Without secondary flow \\
\hline Cohesive banks \\
\hline 4 & Coupled model \\
\hline 5 & Without slump blocks \\
\hline 6 & $\begin{array}{l}\text { Without correction in the velocity } \\
\text { profile }\end{array}$ \\
\hline 7 & Without secondary flow \\
\hline
\end{tabular}

where $u_{b s}$ and $u_{b n}$ are the near-bed velocities in streamwise and transverse directions and $N *$ is the coefficient of the strength of secondary flow (assumed to be 7.0 for simplicity).

\section{NUMERICAL SIMULATIONS}

The coupled numerical model was applied to the experimental conditions of Fukuoka et $\mathrm{al}^{8)}$ in an annular flume for the case of non-cohesive banks.

Furthermore, for the case of cohesive banks, we used the experimental data of Patsinghasanee et $\mathrm{al}^{4)}$ to perform the simulations, even though the experiments were developed in a straight channel. The simulated cases are shown in Table 1.

\section{(1) Non-cohesive banks}

The experiments of Fukuoka et $\mathrm{al}^{8)}$ were developed in an annular flume of 306 degrees. The characteristics of the flume are shown in Fig. 4. The initial conditions and the simulation variables used for the computation are shown in Fig. 3 and Table 2, respectively. The Manning coefficient calculated with the Manning-Strickler equation was 0.014 for the experiment.

The conditions used in the numerical model are very similar to the experimental conditions of $\mathrm{Fu}$ kuoka et al. Nevertheless, the channel length in the experiments is limited, while our model assumes an

Table 2 Simulation variables for non-cohesive banks.

\begin{tabular}{|l|c|c|}
\hline \multicolumn{1}{|c|}{ Variable } & Units & Value \\
\hline Discharge & $\mathrm{L} / \mathrm{s}$ & 2.00 \\
\hline Radius of curvature & $\mathrm{m}$ & 4.50 \\
\hline Internal friction angle & $\circ$ & 30.00 \\
\hline $\begin{array}{l}\text { Bank critical shear } \\
\text { stress }\end{array}$ & $\mathrm{Pa}$ & 0.00 \\
\hline Slope & - & $1 / 400$ \\
\hline Initial Depth & $\mathrm{m}$ & 0.022 \\
\hline
\end{tabular}

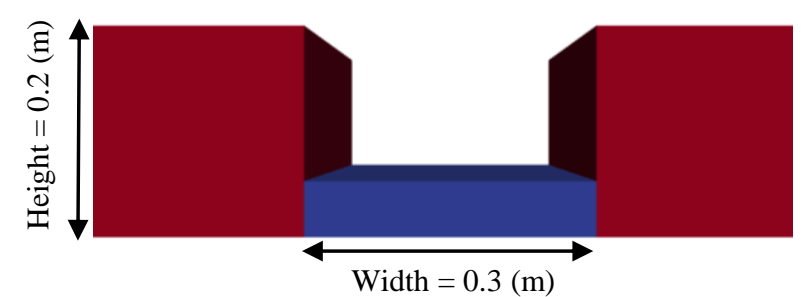

Fig.5 Cross sectional view of the initial conditions for cohesive banks (red: cohesive material; blue: water).

infinitely long channel.

Three cases were simulated: Case 1, Case 2 and Case 3. The first one was performed using the coupled model. Case 2 neglects the correction on the velocity profile with the near-bank velocity and Case 3 was simulated without including the effect of the secondary flow.

\section{(2) Cohesive banks}

The hydraulic conditions of flow and the mechanical properties of the banks used in the numerical simulation are listed in Table 3 and the Manning roughness was set equal to 0.011 .

The radius of the streamline curvature was set to $1.5 \mathrm{~m}$ and the ratio of curvature radius and width becomes five. The critical shear stress and erodibility coefficient were set equal to the values used for the numerical simulations of Patsinghasanee et $\mathrm{al}^{4)}$.

In order to analyze the model qualitatively, four cases were simulated. The initial geometry of the banks used for the simulations can be observed in Fig. 5. Case 4 corresponds to the coupled model including the effect of secondary flow, correction in the velocity profile and the effect of slump blocks. Case 5 neglects the effect of slump blocks, Case 6 does not take into account the correction in the velocity profile and Case 7 neglects the effect of secondary flow.

\section{RESULTS}

\section{(1) Non-cohesive material}

Even though in non-cohesive material we cannot

Table 3 Simulation variables for cohesive banks.

\begin{tabular}{|l|c|c|}
\hline \multicolumn{1}{|c|}{ Variable } & Units & Value \\
\hline Discharge & $\mathrm{L} / \mathrm{s}$ & 6.45 \\
\hline Bank height & $\mathrm{m}$ & 0.20 \\
\hline Channel width & $\mathrm{m}$ & 0.30 \\
\hline Silt clay content & $\%$ & 30.00 \\
\hline Internal friction angle & $\circ$ & 34.30 \\
\hline Slope & - & $1 / 1000$ \\
\hline Radius of curvature & $\mathrm{m}$ & 1.50 \\
\hline Bank cohesion & $\mathrm{Pa}$ & 5.76 \\
\hline
\end{tabular}




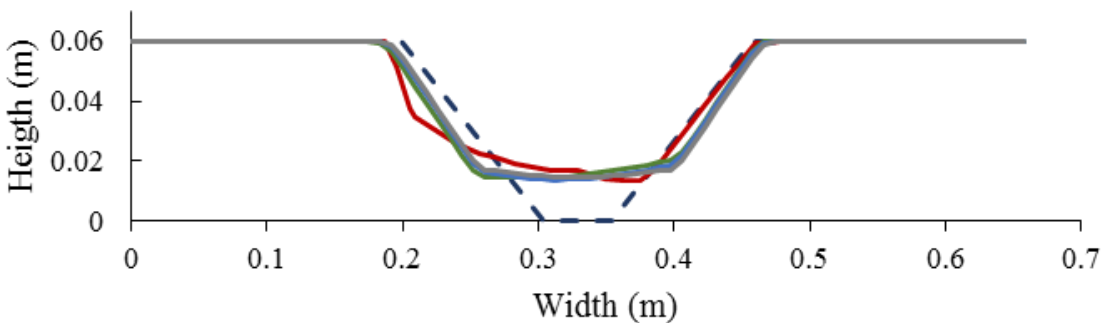

(a)

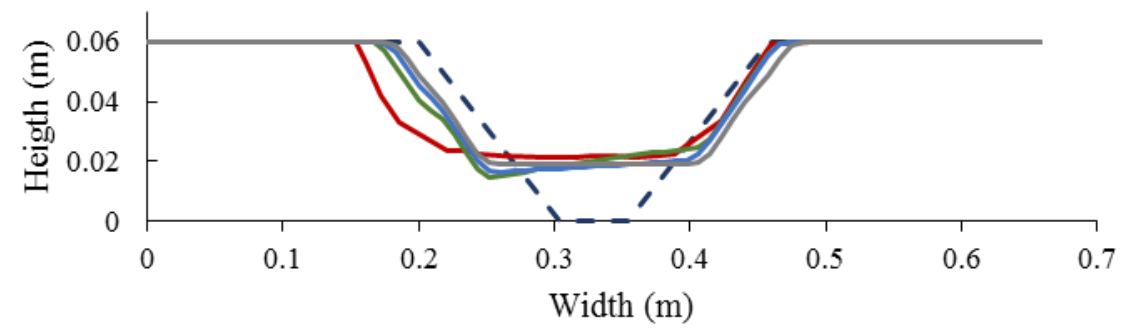

(b)

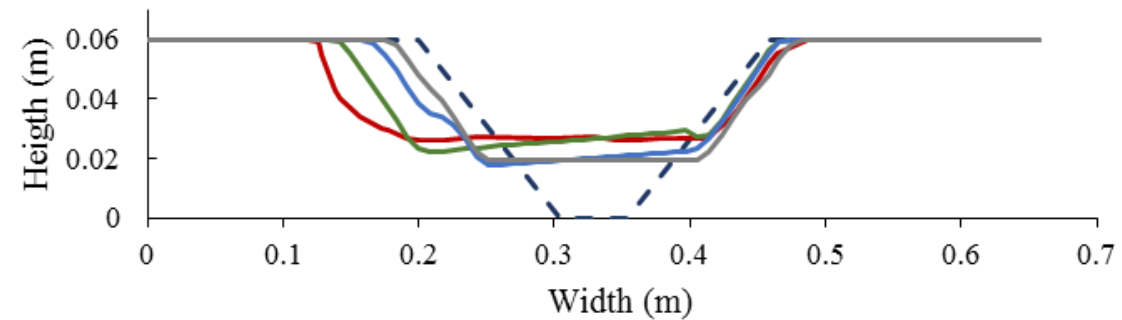

(c)

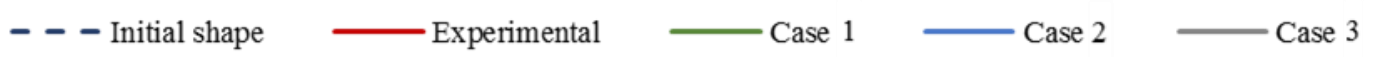

Fig.6 Comparison of the cross sectional views of simulated results for non-cohesive banks and experimental results of Fukuoka et al for Cases 1,2 and 3 at (a) $t=15$ min, (b) $t=60$ min, (c) $t=180$ min (outer bank: left, inner bank: right).

expect slumps blocks, the experimental data of $\mathrm{Fu}-$ kuoka et $\mathrm{al}^{8)}$ was used to validate the coupled numerical model.

The results obtained in the simulations are shown in Fig. 6. At 15 minutes (Fig. 6a), for all cases (Case 1 , Case 2 and Case 3), the results are in good agreement with the cross-sectional shape obtained in the experiment. Nevertheless, after 60 minutes of

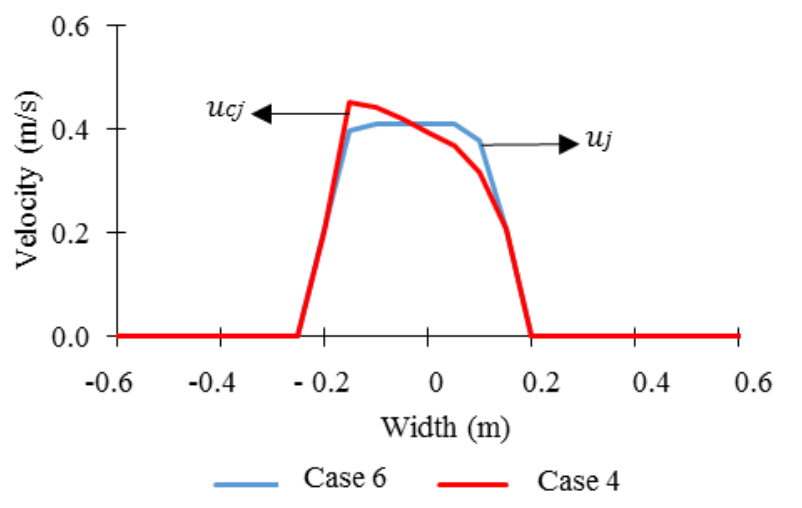

Fig.7 Cross sectional velocity profiles at $t=30$ (s) for Case 4 and Case 6 ( $u_{c j}$ corresponds to corrected velocities and $u_{j}$ velocities prior correction; outer bank: left; inner bank: right). computation, the simulated results underestimate the fluvial erosion in the outer bank as it is observed in Fig 6b.

After 180 minutes of simulation (Fig. 6c), we can see that all the three cases again underestimate the erosion in the outer bank. However, Case 1 presents the best agreement with the cross-sectional shape obtained in the experiment compared with Cases 2 and 3.

\section{(2) Cohesive material}

The results obtained in Case 4 (Fig. 8a) clearly show the collapsed slump blocks in the river bed. In the outer bank (left bank), more fluvial erosion is observed compared to the inner bank (right bank). As a result, a transversal asymmetric triangular cross-sectional shape is developed.

Case 5 (Fig. 8b) shows that without slump blocks, the fluvial erosion increases in both banks, particularly in the outer bank, and therefore the wetted width of the channel becomes wider.

For Case 6 (Fig. 8c), if we neglect the correction of the velocity profile due to curvature, less fluvial erosion can be observed in the outer bank in com- 
parison to Case 4 . The cross sectional velocity profiles for cases 4 and 6 are compared in Fig. 7. Case 6 shows the velocity profile without correction, while Case 4 shows the values of the corrected velocity profile where the velocity is larger in the outer bank.

If we compare Fig. 8a with Fig. 8d, we can observe the effect of the secondary flow. In a bend, faster and deeper flow develops near the outer bank, which causes bank erosion ${ }^{6}$. This effect is not observed when the secondary flow is neglected (Case 7) where the transverse bed slope remains flat along the cross section (Fig. 8d).

\section{DISCUSSIONS}

\section{(1) Non-cohesive material}

For the case of non-cohesive material, the discrepancies between the simulations and the experimental results obtained by Fukuoka et al can be explained by the assumptions considered in the model.

First, we considered an infinitely long circular channel with fully developed flow for the simulations while in Fukuoka et al's experiments, the channel is limited in its length. Furthermore, in their experiments they observed development of bed forms which cannot be represented by our model.

\section{(2) Cohesive material}

The effects of the curvature can be observed both in the transversal bed slope and in the velocity profile in the simulated cross sections.

Regarding the velocity profile, the highest velocities are supposed to be found near the outer side of the bend, and the lowest near the inner side ${ }^{1)}$. Before correcting the velocity profile we could not appreciate this behavior as it was already shown in Fig. 7. After correcting the velocity profile, the model exhibited a more realistic behavior showing higher velocities in the outer bank.

In case of a mobile bed as our case, sediment is transported towards the inner side of the bend due to the secondary current of the first kind until equilibrium state between drag force and gravitational force

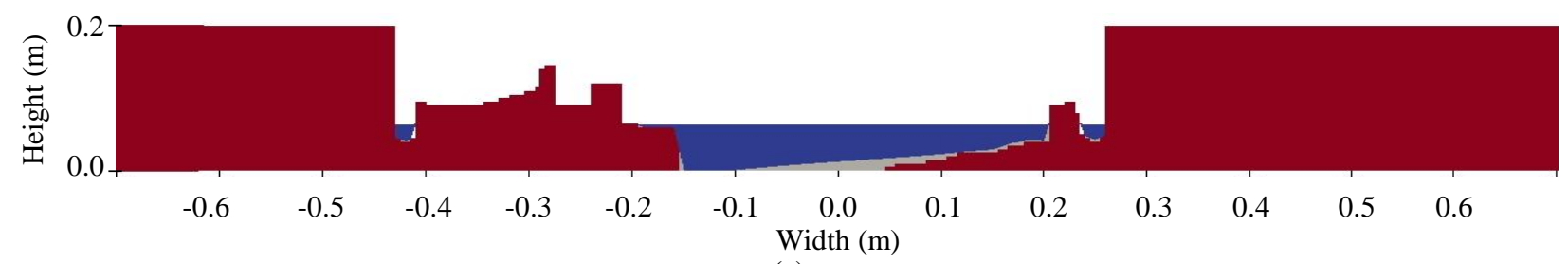

(a)

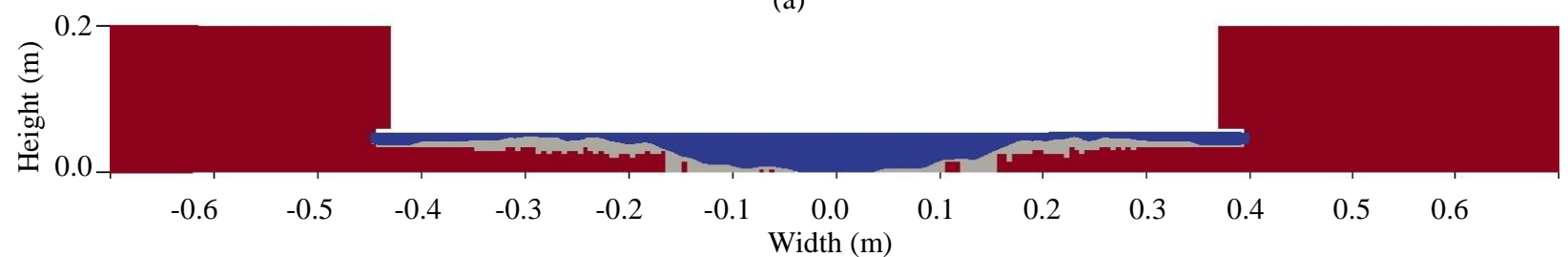

(b)

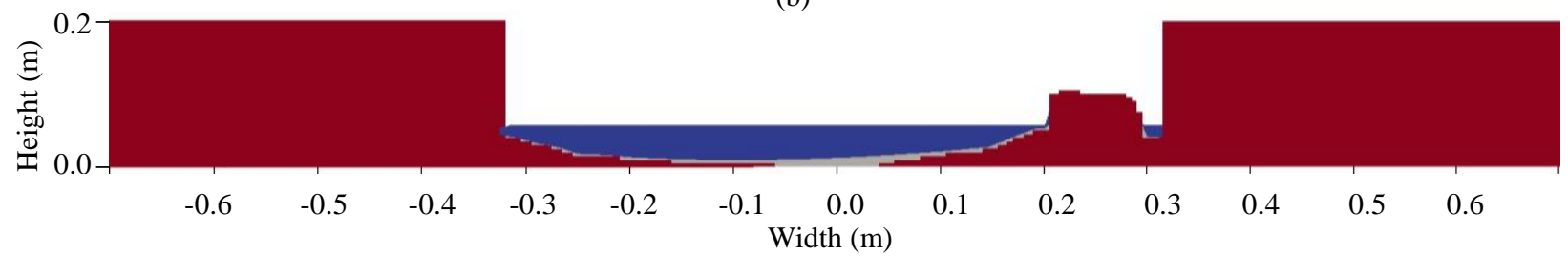

(c)

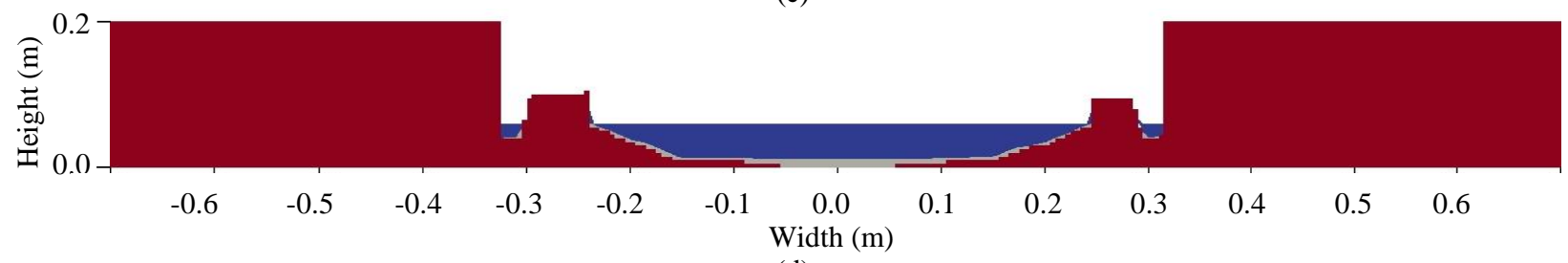

(d)

Fig.8 Cross sectional view of simulated results for cohesive banks at $\mathrm{t}=60 \mathrm{~min}$ for (a) Case 4: Coupled model, (b) Case 5: without slump blocks, (c) Case 6: without correction in the velocity profile and (d) Case 7: without secondary flow (red: cohesive material: grey: non-cohesive bed load; blue: water; outer bank: left; inner bank: right). 
is achieved. This gives a triangular shape to the cross-section (Fig. 8a), with the shallowest part at the inner side (right bank), and the deepest part at the opposite side. In fully-developed bend flow this (dynamic) equilibrium condition is reached everywhere $^{1)}$. In our model, when the secondary flow was neglected, the channel showed a rectangular cross-sectional shape and increased in width symmetrically. In this case, the centrifugal force caused by the curvature of the channel does not drive the flowing water towards the outer side of the bend near the bed; hence the development of the typical triangular transversal shape could not be observed ${ }^{1)}$.

The effect of the slump blocks is evaluated in terms of wetted channel width. The wetted width was larger when the slump blocks were not considered (Fig. 8b), while it became shorter when the effect of slump blocks was included (Fig. 8a). The material that falls in front of the bank (slump blocks) protects the bank. The model considers that the slump blocks still conserve some cohesiveness after falling in the riverbed and therefore, making them more resistant to the fluvial erosion.

If the bank height is relatively small compared with the channel width, slumps blocks have little influence on migration as they are easily carried away by the flow or only protect a small portion of the bank; on the other hand, if the bank height is relatively larger compared with slump blocks may profoundly limit migration ${ }^{3)}$. In this paper, the initial ratio of bank height to channel width equals to 0.67 (including the submerged part) and this value is considered to be much larger than in normal real rivers.

Another aspect we should consider is the difference on the planform channel shape. In the simulation we assume an infinitely long circular channel and the equilibrium state for simplicity. However, in real rivers, the curved part is limited, or the sign of the curvature changes spatially. Therefore, the present computational results are supposed to extremely exaggerate the characteristic of slump blocks. Nevertheless, it is likely that the fundamental behavior of the slump blocks in real rivers are successfully simulated by the present model.

\section{CONCLUSIONS}

The effect of slump blocks in an infinitely long circular channel was studied by means of numerical modeling.

A new coupled model was developed to reach this objective with the following special features: 1) the velocity profile was corrected by a weight function that is in function of the near-bank velocity; 2) the effect of secondary flow was considered in the Hasegawa's equation for lateral sediment transport; and 3 ) the effect of slump blocks was considered. The model was applied to two different materials: cohesive and non-cohesive banks.

For the case of cohesive banks, different cases were tested to evaluate qualitatively the capacities of the numerical model. The results showed that the model is able to reasonably reproduce the effect of slumps blocks in cohesive banks. Furthermore, it was observed that slump blocks protect the bank from fluvial erosion which was observed previously by other authors ${ }^{3), 4), 5 \text { ). }}$

The new characteristics incorporated in the model shows a more realistic behavior for simulating slumps blocks in a circular channel.

For the case of non-cohesive materials, even though the model underestimates the fluvial erosion in the outer bank, the model showed good agreement with the experimental results in terms of the width and the cross-sectional shape.

ACKNOWLEDGMENT: The authors would like to express their sincere thanks to the Japanese Government Scholarships (MEXT) for financial support.

\section{REFERENCES}

1) Crosato, A.: Analysis and modeling of River Meandering, Ph.D. thesis, Delft University of Technology, 2008.

2) Garcia, M., Bittner L. and Nino Y.: Mathematical modeling of meandering streams in Illinois: A tool for stream management and engineering, University of Illinois at Urbana-Champaign, 1996.

3) Motta, D., Abad D., Langeonden J. and Garcia M.: A simplified 2D model for meander migration with physically-based bank evolution, Geomorphology 163-164, 2012.

4) Patsinghasanee S., Kimura I., Shimizu Y. and Nabi M.: Experiments and modeling of cantilever failure for cohesive banks, J. Hydraulic Research., 2017.

5) Patsinghasanee S., Kimura I., Shimizu Y. and Nabi M.: Numerical simulation of a cantilever failure with the effect of slump blocks for cohesive riverbanks, Annual Journal of Hydraulic Engineering, JSCE, Vol.72, No.4, pp.I_493-I_498, 2016.

6) Julian, J.P. and Torres, R.: Hydraulic erosion of cohesive riverbanks, Geomorphology, Vol.76 (1-2), pp.193-206, 2006.

7) Sasaki T.: Cross-section design considering flood controls and environments in meandering channel reaches liable to suffer from disasters, Research Papers of Fukuoka Unit Research and development Initiative, Chuo University, 2016.

8) Fukuoka S., Yamasaka M., Takeuchi S., Furuya A., and Nagaosa E.: Bank erosion in a curved channel, Proceedings of Hydraulics, JSF, pp. 721-726. 1983. 